\title{
Un nuevo paradigma en el fracaso renal agudo
}

\author{
Alberto Tejedor \\ Servicio de Nefrología. Hospital Universitario Gregorio Marañón
}

Como citar este artículo:

Tejedor A. Un nuevo paradigma en el fracaso renal agudo.

Enferm Nefrol. 2019 0ct-Dic;22(4):347-50

\section{Dianas estructurales del fracaso renal agudo}

El fracaso renal agudo es una de las patologías con las que más ha avanzado el conocimiento médico y, sin embargo, menos se ha modificado el tratamiento o el pronóstico.

Con un crecimiento anual de un $25 \%$, el fracaso renal afecta a más de trece millones de personas en el mundo cada año. Cuando aparece en un paciente hospitalizado por otro motivo, aumenta la duración de la estancia media en casi cuatro días. La mortalidad por fracaso renal agudo es mayor que la mortalidad combinada por cáncer de mama, cáncer de próstata, insuficiencia cardíaca y diabetes.

Varios factores pueden estar contribuyendo a esta epidemia mundial que afecta por igual, aunque por distintas causas, a los países del primer mundo tanto como a los subdesarrollados.

- El envejecimiento de la población.

- La aparición de gérmenes más agresivos y resistentes que requieren tratamientos más nefrotóxicos.

- El aumento de la fragilidad en los pacientes seleccionados para tratamientos quirúrgicos, oncológicos y antibióticos cada vez más exigentes.

- El aumento de prevalencia de enfermedades crónicas con un riesgo cardiovascular progresivamente mayor y proporcional al nivel de inflamación.

En nuestro medio, si dejamos de lado los fracasos renales debidos a deshidratación, y los obstructivos por patología prostática, los fracasos renales asociados a sepsis, en el postoperatorio o por toxicidad directa de fármacos nefrotóxicos, son los más frecuentes.

Los segmentos de la nefrona más habitualmente afectadas son (Figura 1):

- El túbulo proximal: debido a su labor de reabsorber casi el $80 \%$ de todo lo que se filtra, está en contacto perpetuo con cualquier nefrotóxico presente en la sangre. Su disfunción reduce la reaparición fisiológica de las proteínas que escapan al filtro glomerular, facilitando la aparición de cilindros proteicos en la orina. Las células tubulares que mueren, se descaman obstruyendo el túbulo e impidiendo el filtrado glomerular.

- El asa de Henle: debido al elevado consumo energético del mecanismo de contracorriente, lleva a cabo una eficiente extracción de oxígeno a nivel molecular. Cuando cae la $\mathrm{pO}_{2}$ por cualquier motivo, el asa de Henle es la primera estructura en resultar dañada. No es de extrañar que los sensores del oxígeno que producen eritropoyetina en función del contenido en $\mathrm{O}_{2}$ de la sangre, se encuentren en los vasos que acompañan a las asas de Henle. Además de las situaciones con hipoxia, algunos fármacos con efecto primario en el túbulo proximal afectan de modo secundario al asa de Henle: son el cisplatino o la gentamicina.

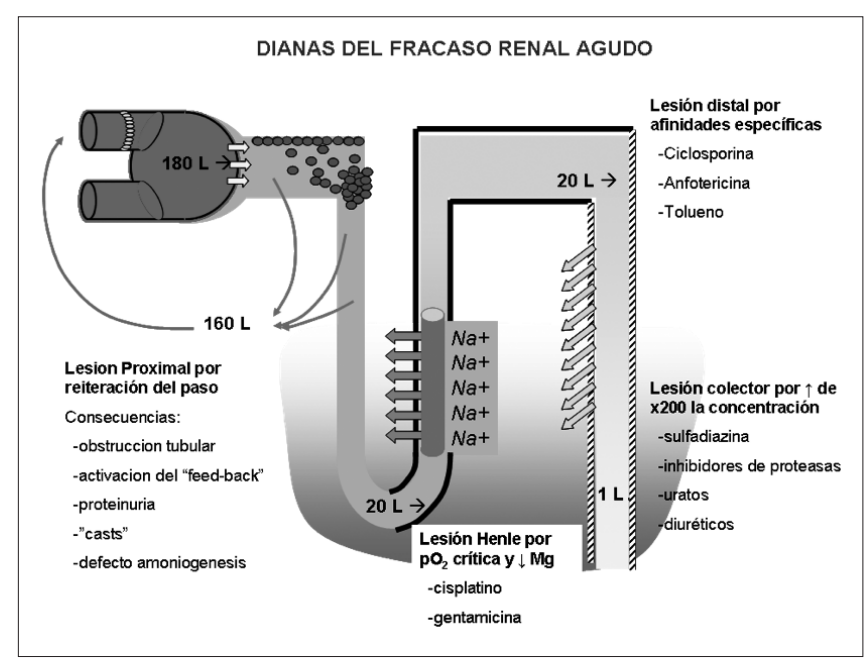

Figura 1. Dianas del Fracaso Renal Agudo a lo largo de la nefrona. (ver explicación en el texto). 
- El túbulo distal: con una afinidad peculiar por algunos tóxicos específicos, como la ciclosporina o la anfotericina.

- El túbulo colector: en el túbulo colector las sustancias filtradas y no reabsorbidas acaban siendo concentradas doscientas veces, lo que puede ocasionar problemas de solubilidad y su precipitación. En el caso de la sulfadiazina (tratamiento de la toxoplasmosis cerebral), los inhibidores de las proteasas (tratamiento del SIDA), la hemoglobina, la mioglobina, las cadenas ligeras de las inmunoglobulinas.

De lejos, el mayor número de fracasos renales se relacionan con el daño directo sobre el túbulo proximal.

\section{El inicio del fracaso renal agudo}

Durante mucho tiempo se ha pensado que cada agresión sobre el riñón provocaba un tipo distinto de fracaso renal agudo. En algunos casos se detectaba la existencia de radicales libres y se asumía que el daño era por oxidación. Pero el uso de antioxidantes no reducía la lesión. En otras ocasiones era a la inflamación a la que se culpaba del fracaso renal, pero el uso de anticuerpos anti interleukinas no conseguía evitar la progresión.

Algunas observaciones eran difíciles de entender, como en el caso del cisplatino. Cisplatino es probablemente el fármaco antitumoral más potente, pero su uso se ve restringido por la toxicidad renal. Cuando se administra cisplatino, y éste entra en las células, se activa formando especies moleculares que se unen rápidamente a ácidos nucleicos y proteínas, rompiendo a los primeros e inactivando a las segundas. Es tan activo que deja de haber cisplatino libre a los 30-60 minutos de su administración. Por supuesto que se sigue detectando en sangre, pero es inactivo ya que va unido a proteínas. Siete días después, las células tumorales y las células renales siguen muriendo, aunque ya no hay fármaco activo circulante.

Estas observaciones las hemos seguido viendo cuando al detectar un fracaso renal agudo, pese a retirar el agente nefrotóxico, el fracaso renal persiste durante días o semanas. Aunque se ha asumido que este efecto de mantenimiento se debía a la persistencia del nefrotóxico en sangre, se observa lo mismo en los nefrotóxicos de eliminación renal que en los de eliminación por otras vías. La realidad supera a la ficción.
Cuando la célula tubular renal es agredida de modo irreversible por cualquier agente nocivo (nefrotóxicos, isquemia, sepsis, mioglobina, hemoglobina...) se activa la apoptosis intrínseca, ya sea por daño primario sobre el ADN (cisplatino), la mitocondria (ciclosporina, contrastes yodados), la membrana celular (gentamicina) 0 el retículo endoplasmático (paracetamol). En la apoptosis intrínseca se activan tanto factores de supervivencia como de muerte. En el plazo de minutos el balance entre unos y otros determinan si la célula tiene alguna posibilidad de sobrevivir, y si no es así, se ponen en marcha procesos intracelulares destinados a asegurar que esa célula lesionada no sobreviva:

- Las mitocondrias resultan literalmente perforadas.

- EI DNA es cortado en trocitos de 120 pares de bases, para asegurar que ningún gen completo de la célula agonizante tiene posibilidad de trasmitirse.

- La célula se deshidrata y condensa, fragmentándose en "cuerpos apoptóticos" que serán fagocitados por las células de alrededor, sin generar aparentemente ninguna reacción inflamatoria aguda.

\section{La expansión del fracaso renal agudo}

Uno de los fenómenos que tienen lugar en las células inicialmente agredidas, incluso si la agresión es soportable, es la expresión en su membrana de Fas, un "receptor de muerte". También procedente de las células dañadas se excreta una molécula soluble Ilamada FasL (ligando de Fas). Cuando FasL se une a su receptor Fas, la parte de la membrana en la que el encuentro se está produciendo, se internaliza y se inicia una segunda oleada de apoptosis. Esta segunda oleada se conoce como apoptosis extrínseca, ya que se origina fuera de la célula. Para que se dé la apoptosis extrínseca, tiene que haber existido una agresión previa inicial.

Esta vía extrínseca es probablemente la pieza del puzzle que nos faltaba para entender el fracaso renal agudo.

Para la apoptosis extrínseca no es necesaria la presencia del agente agresor original. La apoptosis extrínseca se autoperpetúa y es común para la mayoría de los fracasos renales agudos. Esta fase de extensión o expansión del fracaso renal agudo tiene varias vías de amplificación (Figura 2):

- Se producen radicales libres que a su vez causan muerte celular y perpetúan el daño. 


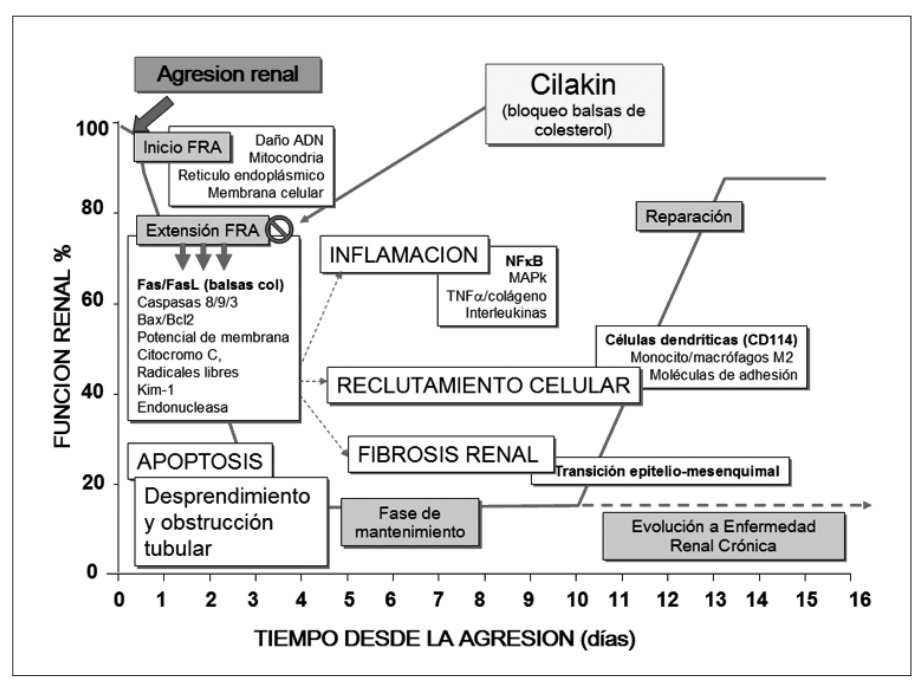

Figura 2. Evolución temporal del Fracaso Renal Agudo: fases de Inicio, extensión, mantenimiento y reparación o evolución a la cronicidad. Se presentan los eventos moleculares derivados de la activación de la apoptosis extrínseca en la fase de expansión, y el efecto protector del bloqueo de las balsas de colesterol.

- Se activan vías que creíamos eran inflamatorias y que en realidad van destinadas a proporcionar solidez al órgano lesionado: se activa la síntesis de colágeno, se inhiben sus vías de degradación y se cambian las señales de la insulina.

- Las células dendríticas peritubulares detectan de algún modo que se está produciendo muerte celular, porque emigran a los pocos minutos hacia los ganglios linfáticos de la zona, donde se activa un tipo especial de macrófago, el M2.

- Unas horas después de la emigración de las células dendríticas, los M2 llegan a la zona de la lesión. A ese nivel, la apoptosis extrínseca ha inducido la expresión en el endotelio del capilar peritubular de moléculas de adhesión, que son identificadas por los M2, que salen del capilar en la zona lesionada.

La apoptosis extrínseca se extiende como las olas de un estanque al arrojar una piedra, a partir de la zona primariamente lesionada. Es decir, alrededor de la zona lesional se produce un gradiente de Fas/FasL que se va reduciendo con la distancia. Este gradiente se establece también a nivel de la señalización para los M2 que se mueven buscando el área de mayor expresión de moléculas de adhesión.

La activación de la apoptosis extrínseca hace que en un tiempo récord de menos de 48 horas, las células tubu- lares aún vivas comiencen a desdiferenciarse, abandonando un fenotipo trasportador por otro de bajo perfil. Esta transición epitelio-mesenquimal es la responsable de la aparición del $70 \%$ de los fibroblastos que invaden la zona renal lesionada. Hay un $30 \%$ que procede de la circulación. Hace tiempo creíamos que la aparición de fibroblastos en un fracaso renal agudo se debía a la desaparición de las células tubulares muertas, que eran sustituidas por fibroblastos, y que su presencia marcaba la irreversibilidad del proceso. Hoy sabemos que esto no es así. El proceso se inicia mucho antes, y es reversible.

\section{¿Es posible frenar la fase de expansión del fracaso renal agudo?}

La respuesta es afirmativa.

El "punto crítico" de la apoptosis extrínseca es el elemento iniciador: la formación del complejo Fas/FasL a nivel de la membrana celular. La diana no son las asas de amplificación: los antioxidantes no sirven; los antiTNF alfa no sirven.

Por otro lado, intentar bloquear directamente la señalización a nivel de Fas supone dejar al cisplatino sin capacidad tumoricida, a la ciclosporina sin actividad linfocitolítica o a vancomicina sin capacidad antibiótica.

Sin embargo, sí es posible bloquear el complejo Fas/ FasL exclusivamente a nivel renal sin interferir con la señalización a otros niveles.

El complejo Fas/FasL se encuentra situado en una estructura concreta y compleja de la membrana celular: la "balsa de colesterol". Cuando el complejo se forma, se internaliza la balsa entera. En la balsa, el complejo Fas/FasL comparte ubicación con numerosos enzimas y receptores de membrana anclados a la misma estructura. Los inhibidores de dichos enzimas o receptores impiden la internalización de las balsas, bloqueando toda la fase de expansión del fracaso renal agudo y sus distintas asas de amplificación con una sola maniobra. Basta con identificar una diana que solo exista en el riñón y se localice en las balsas para bloquear o reducir en gran medida todos los fracasos renales agudos que usan esta vía de expansión. Una de esas dianas ha sido la dehidropeptidasa renal tipo I. Un enzima destinado a romper los enlaces peptídicos entre prolina y cualquier otro aminoácido. Y el inhibidor que hemos usado es Cilakin, una molécula específica que simula un di- 
péptido y que se une y bloquea a la deshidropeptidasa I renal. Ninguna relación con Fas, o con FasL, ninguna capacidad antioxidante ni antiinflamatoria. Pero cuándo Cilakin bloquea la internalización de las balsas con el complejo Fas/FasL:

- No se activan las cascadas de la apoptosis extrínseca. - No se lesionan las mitocondrias ni se hidroliza el ADN. - No se activa la formación de radicales libres.

- No hay activación de células dendríticas ni infiltración por monocitos.

- No hay transición epitelio-mesenquimal.

Cilakin ha mostrado su capacidad para impedir el fracaso renal agudo por cisplatino, gentamicina, vancomicina, contrastes yodados, ciclosporina o tacrolimus. Evita el fracaso renal por hierro en la hemólisis aguda o en la rabdomiólisis. Evita el fracaso asociado a la sepsis.

En el momento actual, Cilakin ha pasado con éxito la Fase 1 de su estudio en humanos y está a la espera de los ensayos en Fase 2.

Es posible que en un futuro no muy lejano se puedan desarrollar otros ligandos específicos para la balsa de colesterol renal que puedan sumarse al arsenal terapéutico de una nueva clase de fármacos de los que $\mathrm{Ci}$ lakin es el primer exponente.

\section{Bibliografía}

1. Bernadette Thomas, Kunihiro Matsushita, Kalkidan Hassen Abate, et al, on behalf of the Global Burden of Disease 2013 GFR Collaborators, CKD Prognosis Consortium, Global Burden of Disease Genitourinary Expert Group. Global Cardiovascular and Renal Outcomes of Reduced GFR. JASN Jul 2017, 28 (7) 2167-2179; DOI: 10.1681/ASN.2016050562.

2. Valerie A Luyckx a, Marcello Tonelli b \& John W Stanifer. The global burden of kidney disease and the sustainable development goals. Bulletin of the World Health Organization 2018;96:414-422D. doi: http:// dx.doi.org/10.2471/BLT.17.206441.
3. Chevalier RL. The proximal tubule is the primary target of injury and progression of kidney disease: role of the glomerulotubular junction. Am J Physiol Renal Physiol. 2016 Jul 1;311(1):F145-61. doi: 10.1152/ ajprenal.00164.2016. Epub 2016 May 18. PMID: $27194714 ;$ PMCID: PMC4967168.

4. Basile DP, Anderson MD, Sutton TA. Pathophysiology of acute kidney injury. Compr Physiol. 2012 Apr;2(2):1303-53. doi: 10.1002/cphy.cl10041. PMID: 23798302; PMCID: PMC3919808.

5. Tejedor A.: Alteraciones celulares en el Fracaso Renal Agudo. En: Fracaso Renal Agudo. Ed. F. Liaño. Ed Masson, Madrid, 2000. 17-44.

6. Okusa MD, Chertow GM, Portilla D; Acute Kidney Injury Advisory Group of the American Society of Nephrology. The nexus of acute kidney injury, chronic kidney disease, and World Kidney Day 2009. Clin J Am Soc Nephrol. 2009 Mar;4(3):520-2. doi: 10.2215/CJN.06711208. Epub 2009 Feb 18. PMID: 19225036; PMCID: PMC4571532.

7. Ortiz A, Tejedor A, Caramelo C. Nephrotoxicity. En: Drug-Induced Mitocondrial Disfunction. Editado por JA Dykens e Yvonne Will. Ed. Wiley. Hoboken, New Jersey. 2008. p. 291-310.

8. Ortiz A, Tejedor A, Rodríguez Pujol D.: Fisiopatología del Fracaso renal agudo. En: Nefrología Clínica. Ed. Hernando Avendaño L. $3^{\text {a }}$ ed. Medical Panamericana. Madrid 2009. 739-47.

9. Humanes B, Jado JC, Camaño S, López-Parra V, Torres AM, Álvarez-Sala LA, Cercenado E, Tejedor A, Lázaro A. Protective Effects of Cilastatin against Vancomycin-Induced Nephrotoxicity. Biomed Res Int. 2015;2015:704382.

10. Humanes B, Camaño S, Lara JM, Sabbisetti V,González-Nicolás MA Bonventre JV, Tejedor A, Lázaro A. "Cisplatin-induced renal inflammation is ameliorated by cilastatin nephroprotection". Nephrol Dial Transplant. 2017 Mar 11. doi: 10.1093/ndt/gfx005.

Este artículo se distribuye bajo una Licencia Creative Commons Atribución-NoComercial 4.0 Internacional. https://creativecommons.org/licenses/by-nc/4.0/ 